\title{
GYNODIOECY IN SILENE VULGARIS (CARYOPHYLLACEAE): PROGENY SUCCESS, EXPERIMENTAL DESIGN, AND MATERNAL EFFECTS ${ }^{1}$
}

\author{
Claudia L. Jolls ${ }^{2,3}$ and Thomas C. Chenier ${ }^{4}$ \\ ${ }^{2}$ Department of Biology, East Carolina University, Greenville, North Carolina 27858-4353 and \\ ${ }^{3}$ University of Michigan Biological Station, Pellston, Michigan 49769; and \\ ${ }^{4}$ Department of Biostatistics and Epidemiology, East Carolina Universiy, Greenville, North Carolina 27858-4353
}

\section{A B S T R A C T}

This study documents the comparative success of seeds and seedlings of the perennial gynodioecious-gynomonoecious weed, Silene vulgaris, in the greenhouse. The importance of experimental design is stressed by comparing two different statistical analyses of the data. Seeds were obtained from artificial pollinations in the field: self-fertilization of hermaphrodites, and crossfertilizations of both hermaphrodites and females. One-way analysis of variance using progeny type (selfed hermaphrodites, outcrossed hermaphrodites, and outcrossed females) as the treatment effect for each seed and seedling variable showed statistically discernable differences among progeny from different cross types. The significance of this type of ANOVA resulted from a reduced error term and positively-biased $F$ ratios. A factorial design showed no significant differences due to type of progeny in seed mass, days to germination, leaf number, area, or biomass at six weeks of age. There were, however, significant differences among seeds attributable to maternal parent for all seed and seedling variables. A higher proportion of seeds from outcrossed individuals germinated compared to that from self-fertilization. When the data were analyzed to include and partition all sources of variation, differences among offspring appeared during germination, rather than during later development. Seed mass, cross type, and sex of maternal parent all significantly affected the likelihood of germination; however, they had decreasing predictive power, respectively. Inbreeding depression in Silene vulgaris may help maintain gynodioecy; however, the pleiotropic effects of both nuclear and cytoplasmic genes for sex expression also may affect fitness and the maintenance of females.

THE TERM "gynodioecious" was used by Darwin (1877) for Thymus serpyllum to describe the occurrence of females and hermaphrodites within the same population of a plant species. Since that time, many hypotheses have attempted to explain the occurrence of two dif-

\footnotetext{
' Received for publication 19 September 1988; revision accepted 9 March 1989.

We appreciate support from the Naturalist-Ecologist Training Program, Andrew W. Mellon Foundation, of the University of Michigan Biological Station, the Research and Creative Activity Committee of the Faculty Senate of East Carolina University, and the Southern Regional Education Board. Special thanks to Chiquita Culberson, Department of Botany, Duke University, Robert J. Downs, Judith J. Thomas, Clyde M. Farrell and the staff of the Southeastern Plant Environment Laboratory, North Carolina State University, and to Wade L. Bryant, Laura K. Gillikin, Mark R. Luttenton, Ann Maureen D. Otte, and Sondra Padley. Additional statistical consultation from Gary Fowler, Kevin F. O'Brien, Donald Holbert, Marsha Shepherd, and Doug Deutschman is very much appreciated. This manuscript was thoughtfully reviewed by Deborah Charlesworth, Michael C. Grant, A. R. Kruckeberg, Ann K. Sakai, Mark A. Schlessman, and Stephen G. Weller, and completed while CLJ was the recipient of a Research Opportunity Award, NSF BSR-40464, at the University of Colorado. My colleagues at the Department of Environmental, Population, and Organismic Biology, particularly Jane $\mathbf{H}$. and Carl L. Bock, are most appreciated.
}

ferent forms of breeding individuals within the same population. If sex expression is controlled by nuclear inheritance, females are at a selective disadvantage relative to hermaphrodites due to their loss of male function. Compensation must exist that enables females to surpass hermaphrodites in some component(s) of fitness (Lewis, 1941; Lloyd, 1975, 1976; Ross, 1978; Charlesworth and Charlesworth, 1978; Charlesworth, 1981). Reported advantages of females over hermaphrodites include greater numbers of flowers per plant, ovules per flower, adult survivorship, seeds per plant, greater seed weight, or progeny success (Darwin, 1877; Connor, 1973; Assouad et al., 1978; Philipp, 1980; Kesseli and Jain, 1984; Van Damme and Van Delden, 1984; Schrader, 1986; Shykoff, 1988).

Hypotheses used to explain the evolution and maintenance of gynodioecy are of two general types-those dealing with the adults and those dealing with the progeny. First, adult females may exhibit greater fitness than hermaphrodites due to overdominance (Ross, 1978; Gregorius, Ross, and Gillet, 1982; Van Damme, 1984) or to pleiotropic action of genes for sex, i.e., direct effects of genetic factors causing sterility on progeny fitness (Van Damme, 
1984). As adults, rather than a genic advantage per se, females may reallocate resources saved due to male sterility and exhibit greater fecundity (Darwin, 1877), greater longevity (Van Damme, 1984), greater vegetative spread (Stevens and Richards, 1985), or greater colonizing ability (Gouyon and Couvet, 1985).

The second general class of hypotheses posed to explain the maintenance of females among hermaphrodites deals with the relative success of offspring from females and hermaphrodites. Gynodioecy is typically associated with selfcompatibility (Lewis, 1941; Jain, 1961; Valdeyron, Dommée, and Valdeyron, 1973; Ganders, 1978). In self-compatible taxa, females are obligately outcrossed; hermaphrodites may self-fertilize. Empirical and theoretical studies hypothesize that female plants are maintained in a population among hermaphrodites due to the greater fitness conferred on the progeny from obligate outcrossing of unisexual mothers (Lewis, 1941; Valdeyron et al., 1973). The progeny of females, produced by obligate outcrossing, may exhibit heterosis or avoid inbreeding depression (Valdeyron et al., 1973; Dommée and Jacquard, 1985). Such work has dealt with seed number and seed mass (Vaarama and Jääskeläinen, 1967; Connor, 1965, 1970; Webb, 1981; Schrader, 1986). Differences in seed number between the sexes, however, do not always explain the maintenance of male sterility. Van Damme and Van Delden (1984) stress the importance of different phases of the life cycle as sources of fitness differences between the sexes.

This study documents the comparative success of seeds and seedlings of the perennial weed, Silene vulgaris (Moench) Garcke (Caryophyllaceae), in a controlled environment. We observed germination and seedling morphology and biomass, and related these characters to seed mass, type of cross, and sex of the maternal parent. If gynodioecy is adaptive because it promotes outcrossing, we hypothesized that the progeny of females and those resulting from cross-fertilized hermaphrodites would be more successful in germination or growth than those from selfed hermaphrodites.

STUDY ORGANISM - Silene vulgaris (Moench) Garcke (Silene cucubalus sensu accut non Wibel) is an herbaceous, perennial member of the Caryophyllaceae, widely distributed in Europe, Asia, North Africa, and North America. This weedy introduced taxon occurs throughout North America, from north of the Arctic Circle south into the southern Great Plains, and west from the eastern seaboard to the intermountain region and the northwestern United States (Shetler and Skog, 1978). This species is present in a variety of disturbed habitats, including zinc-lead mine wastes (Lefebvre and Simon, 1979) and gravel banks (Lubke and Cavers, 1970). Diploid and tetraploid populations exist (Morrisset, 1966). Considerable variation in plant growth form has been reported (Aeschimann and Bocquet, 1980), including stoloniferous tetraploids in Israel (Dulberger and Horovitz, 1984). Within populations, three types of individual may occur: hermaphrodites bearing perfect flowers, females bearing only pistillate flowers with rudimentary anthers, and gynomonoecious plants having both forms of flowers, varying in degree of male function. Based on the published literature and five years of personal observation, individuals do not change sex.

MATERIALS AND METHODS-This study was based at the Universiy of Michigan Biological Station at Douglas Lake, Pellston, in northern lower Michigan $\left(45^{\circ} 33^{\prime} 30.370^{\prime \prime} \mathrm{N}\right.$, $84^{\circ} 40^{\prime} 27.516^{\prime \prime} \mathrm{W}$, Cheboygan Co., T37N, R3W, Sec. 33). The data presented were collected from plants randomly selected from over 250 permanently tagged individuals in disturbed sites on UMBS grounds. During 1985, we obtained seeds from selfed hermaphrodites, outcrossed hermaphrodites, and outcrossed females by artificially pollinating individuals in natural stands at UMBS. Natural pollinations were prevented by excluding pollinators with fine mesh bags. Although hermaphrodites are strongly protrandrous, these individuals were emasculated to prevent autogamy. Outcrossed individuals received mixed pollen loads, collected immediately prior to hand pollination from at least five other individuals within a 1 ha area of the parent. Care was taken to fully load receptive stigmas uniformly and minimize the effects of mixed genotype interactions and pollen abundance on seed set. Seeds and capsules matured on the maternal parent and then were harvested. A sample of twenty seeds was selected without bias from each plant. Twenty seeds were similarly selected from those same seven hermaphrodites which had been crossed and selfed, and from six different female plants, also cross-pollinated. Seeds were stored at room temperatures for seven months in manila envelopes after harvest.

Four hundred seeds were weighed individually to the nearest $0.0001 \mathrm{mg}$ on a Cahn Model 26 Electrobalance (Cerritos, CA) and randomly arrayed with respect to sex of maternal parent, type of cross, and parental genotype in styrofoam cups filled with a 50:50 mix of sand, peat 
TABLE 1. Analysis of variance table comparing mean seed mass among groups of progeny from selfed hermaphrodites, outcrossed hermaphrodites, and outcrossed females

\begin{tabular}{lcrrrr}
\hline \hline \multicolumn{1}{c}{ Source } & Sum of squares & \multicolumn{1}{c}{ df } & Mean squares & \multicolumn{1}{c}{$F$} & $P$ \\
\hline Group & 1.1201 & 2 & 0.5605 & 3.00 & 0.0862 \\
Parent (group) & 2.8257 & 16 & 0.1766 & 12.99 & 0.0001 \\
Seed & 0.1090 & 7 & 0.0156 & 0.65 & 0.7093 \\
Seed * group & 0.3347 & 14 & 0.0239 & 1.76 & 0.0536 \\
Seed * parent (group) & 1.5268 & 112 & 0.0136 & & \\
Total & 5.8867 & 151 & & & \\
\hline
\end{tabular}

and vermiculite ("peat-lite," Redi Earth, W. R. Grace Co.). Each seed was sown on a thin layer of builders' sand for visibility. Cups were placed in an unshaded temperature controlled greenhouse, $22 / 18 \mathrm{C}$ day/night, 9/15 hr light/ dark cycle. The dark period was interrupted between 1100 and 0200 with 550-600 lux from incandescent filament lamps. For the first three weeks, all seedlings were misted one minute every $15 \mathrm{~min}$ under shade cloth and received a nutrient solution of 50:50 modified Hoagland's : deionized water (Downs and Thomas, 1983). After three weeks, the shade cloth was removed; water was decreased slowly to one minute of mist three times daily. The experiment began on 15 April 1986 when seeds were sown and ended after six weeks on 30 May with harvest of aboveground parts of the plants.

For the seeds which germinated, number of leaves per week, height of the plant, leaf area, and biomass of the seedling at the end of six weeks were recorded. The number of expanded leaves was counted. Leaf area was determined by separation of each leaf from the plant and calculated to the nearest $0.01 \mathrm{~cm}^{2}$ using a LiCor leaf area meter. Aboveground parts were dried for $24 \mathrm{hr}$ at $70 \mathrm{C}$ and weighed to the nearest $0.0001 \mathrm{~g}$.

Analysis-Three types of progeny were represented: those obtained from selfed hermaphrodites, outcrossed hermaphrodites, and outcrossed females. Data were analyzed with ANOVA using seed mass and other seedling characters as dependent variables, and progeny type and seeds within parent as treatment variables. We used a split-plot factorial design (also known as a randomized block design with replication, Kirk, 1982) where progeny type represented the group variable and seed acted as a replication. This design is appropriate for repeated measures (seeds) for each subject (maternal parent) when subjects are nested within treatments (progeny type). We specified the variation among seeds to represent a random effect; as a result, a quasi- $F$ ratio (Kirk, 1982) was calculated for the group effect (progeny type). We also deleted from the analysis one female parent having only one of the twenty seeds germinate. To balance the design, we randomly selected eight progeny that survived the six weeks of the study from the twenty seeds for each cross. This random selection of eight replicates for each parent and cross combination was repeated several times. The means and standard errors for these data are essentially the same as those in the larger data set. As a result, in all cases, the conclusions from the split-plot factorial ANOVA were the same. Means of the three groups (selfed hermaphrodites, outcrossed hermaphrodites, and outcrossed females) also were compared using a one-way analysis of variance. Each seed was treated as a replicate of one of the three types of progeny and no nesting or blocking of seeds within maternal parents was done. In both designs, we used transformations to meet assumptions of normality and homoscedasticity where necessary.

RESULTS-The average mass of individual seeds did not differ among progeny types $(P=$ $0.0862)$ nor within replicate seeds of a cross $(P=0.7093$, Table 1). No significant interaction among progeny type, maternal parent and/or seed was observed. Similarly, the different groups of progeny produced could not be statistically discerned using this analysis for the number of days until germination (Table 2), number of leaves per seedling at six weeks (Table 3), total leaf area (Table 4), or total aboveground biomass (Table 5). There was some concern about the normality of the variables days until germination, leaf number, and leaf area. The ANOVA of the transformed data, however, yielded the same results. In short, there were no significant differences due to any of the treatment variables. There was, however, a significant difference due to maternal parent for each of the dependent measures among those plants that survived for six weeks. We concluded that the type of cross is not likely 
TABLE 2. Analysis of variance table comparing mean days to germination among groups of progeny from selfed hermaphrodites, outcrossed hermaphrodites, and outcrossed females

\begin{tabular}{lrrrrr}
\hline \multicolumn{1}{c}{ Source } & Sum of squares & \multicolumn{1}{c}{ df } & Mean squares & \multicolumn{1}{c}{$F$} \\
\hline Group & 17.693 & 2 & 8.847 & 0.41 & 0.6707 \\
Parent (group) & 314.136 & 16 & 19.634 & 2.96 & 0.0004 \\
Seed & 64.116 & 7 & 9.159 & 1.10 & 0.4143 \\
Seed * group & 116.668 & 14 & 8.330 & 1.25 & 0.2503 \\
Seed * parent (group) & 737.293 & 112 & 6.643 & & \\
Total & $1,249.906$ & 151 & & & \\
\hline
\end{tabular}

to affect these variables for those progeny that germinate. Differences among progeny success, however, were in part due more to differences among maternal genotype than to differences in sex of maternal parent or type of mating.

We then compared germinability of seeds in each of the three types of crosses. A test for the equality of proportion of seeds germinating from each class of progeny indicated that a different proportion of germination occurred for each group $\left(\chi^{2}=14.35, \mathrm{df}=2, P<0.001\right.$, Table 6). Progeny from outcrossed hermaphrodites were more likely to germinate than those from selfed hermaphrodites $\left(\chi^{2}=14.53, \mathrm{df}=\right.$ $1, P<0.001)$. Specifically, $76 \%$ of the seeds from selfed hermaphrodites, $93 \%$ from the outcrossed hermaphrodites, and $83 \%$ from outcrossed females germinated.

To assess the relative effects of seed mass, parent sex, and type of cross on germination, we implemented a logistic regression. A logistic regression is appropriate when the dependent variable exists as a binary character state, i.e., whether or not germination occurred. Germination was the dependent variable (no or yes), and seed mass, sex of maternal parent ( 0 $=$ hermaphrodite, $1=$ female), and cross type $(0=$ outcrossed, $1=$ selfed $)$ were the predictor variables. All three of these variables were related to the likelihood of germination (Table 7). From the magnitude of the $\chi^{2}$ values, we can assess the predictive power of each of the variables. Seed mass, cross type, and sex of maternal parent, respectively, were decreasingly effective in predicting whether a seed ger- minated. Larger seeds were more likely to germinate than smaller ones. Seeds from outcrossed hermaphrodites were more likely to germinate than those from females or selfed hermaphrodites. Based on the logistic regression and using mean seed mass as a typical value, we estimated that the likelihood of germination was 0.827 for seed from selfed hermaphrodites, 0.950 for outcrossed hermaphrodites, and 0.906 for outcrossed females.

A one-way ANOVA was performed on each of the five seed and seedling variables to compare this design with the more complex splitplot factorial. We used the three types of progeny as group effects and seeds within these progeny types as replication. We transformed data where appropriate to meet the assumptions of ANOVA. Duncan's, Student-Newman-Keuls, and Scheffé's a posteriori contrasts were used to determine whether the three progeny classes differed from one another. This approach to the data analysis resulted in strikingly different conclusions than those generated from the 3,20 split-plot factorial design. The one-way analysis demonstrated significant differences among progeny types for seed mass, days until germination, leaf number, leaf area, and aboveground biomass (Table 8 ). The means and standard deviations reported for the variables in Table 8 are essentially the same as those for variables in Tables $1-5$. The one-way ANOVA would have us conclude that seeds from outcrossed females were significantly heavier than those from either mating of hermaphrodites. Similarly, using a one-way de-

TABLE 3. Analysis of variance table comparing mean number of leaves among groups of progeny from selfed hermaphrodites, outcrossed hermaphrodites, and outcrossed females

\begin{tabular}{lrrrrr}
\hline \multicolumn{1}{c}{ Source } & Sum of squares & \multicolumn{1}{c}{ df } & Mean squares & \multicolumn{1}{c}{$F$} \\
\hline Group & 26.4308 & 2 & 13.2154 & 0.53 & 0.5885 \\
Parent (group) & 372.0430 & 16 & 23.2529 & 2.87 & 0.0006 \\
Seed & 151.0981 & 7 & 21.5854 & 2.38 & 0.0793 \\
Seed * group & 126.7659 & 14 & 9.0547 & 1.12 & 0.3485 \\
Seed * parent (group) & 908.1292 & 112 & 8.1083 & & \\
Total & $1,611.4670$ & 151 & & & \\
\hline
\end{tabular}


TABLE 4. Analysis of variance table comparing mean leaf area among groups of progeny from selfed hermaphrodites, outcrossed hermaphrodites, and outcrossed females

\begin{tabular}{lrrrrr}
\hline \multicolumn{1}{c}{ Source } & Sum of squares & \multicolumn{1}{c}{ df } & Mean squares & $F$ & $P$ \\
\hline Group & 137.019 & 2 & 68.5095 & 1.40 & 0.2782 \\
Parent (group) & 767.109 & 16 & 47.9443 & 3.04 & 0.0003 \\
Seed & 168.188 & 7 & 24.0269 & 1.43 & 0.2690 \\
Seed * group & 235.005 & 14 & 16.7861 & 1.06 & 0.4013 \\
Seed * parent (group) & $1,767.780$ & 112 & 15.7838 & & \\
Total & $3,075.101$ & 151 & & & \\
\hline
\end{tabular}

sign, we would conclude that progeny from outcrossed females germinated more quickly than those from selfed hermaphrodites, by nearly one day. Seeds from selfed hermaphrodites produced seedlings that were significantly inferior to other types of offspring with respect to leaf number, leaf area, and aboveground biomass.

Discussion-We observed significant differences among progeny from selfed hermaphrodites, outcrossed hermaphrodites, and outcrossed females of Silene vulgaris. When all sources of variation were included, differences in many characters among the three types of progeny were attributable to differences among mothers, not the type of mating. The likelihood of germination in the bladder campion, at least in the greenhouse, however, was related to whether pollination is xenogamous or geitonogamous and sex of maternal parent.

Significant differences in seed mass occur within Silene vulgaris. These differences, however, are found among maternal parents and are not attributable to outcrossing or selfing. In contrast to our results, mass or size of individual seeds from selfed hermaphrodites has been reported to be less than those from crossfertilization (Connor, 1965, 1970; Schrader, 1986). Such differences, however, do not always occur (Vaarama and Jääskeläinen, 1967; Webb, 1981). While Darwin (1877) reported seed mass from females was larger than that from hermaphrodites in Euonymus europaeus, Webb (1979) found no significant differences in the same species. Furthermore, many studies do not account for variation within and among plants relative to that among the types of progeny.

Germinability of seeds in Silene vulgaris seems to be favored by outcrossing, particularly for progeny from females compared to those from selfed hermaphrodites. Even when the influence of seed mass was removed, type of cross and sex of maternal parent were significant predictors of whether a seed germinated. Greater germination of seeds from females relative to those from selfed hermaphrodites has been found for other taxa (Vaarama and Jääskeläinen, 1967; Connor, 1973; Assouad et al., 1978; Schrader, 1986; Shykoff, 1988). A greater percentage of seeds from females may be more likely to germinate than from selfed hermaphrodites, however, the speed of germination (as germination rate or days to germination) is often equal among parent sexes and cross type (Vaarama and Jääskeläinen, 1967; Schrader, 1986; Shykoff, 1988).

The maintenance of females among hermaphrodites may relate to the success of their offspring, particularly relative to inbred individuals. Other researchers have found progeny from females are more successful than their counterparts from hermaphrodites, particularly from selfed individuals (Cortaderia richardii, Connor, 1973; Thymus vulgaris, Assouad et al., 1978; Stellaria longipes, Philipp, 1980; Gingidia montana, Webb, 1981). Webb (1981) and Connor (1973) reported larger seedlings from females than hermaphroditic

TABLE 5. Analysis of variance table comparing mean biomass among groups of progeny from selfed hermaphrodites, outcrossed hermaphrodites, and outcrossed females

\begin{tabular}{lcrccc}
\hline \hline \multicolumn{1}{c}{ Source } & Sum of squares & df & Mean squares & $F$ & $P$ \\
\hline Group & 0.00405 & 2 & 0.00053 & 1.29 & 0.3114 \\
Parent (group) & 0.00690 & 16 & 0.00043 & 2.15 & 0.0106 \\
Seed & 0.00153 & 7 & 0.00022 & 1.22 & 0.3546 \\
Seed * group & 0.00246 & 14 & 0.00018 & 0.90 & 0.5609 \\
Seed * parent (group) & 0.02284 & 112 & 0.00020 & & \\
Total & 0.03509 & 151 & & & \\
\hline
\end{tabular}


TABLE 6. Contingency table comparing frequency of germination among progeny of selfed hermaphrodites, outcrossed hermaphrodites, and outcrossed females

\begin{tabular}{lcc}
\hline & \multicolumn{2}{c}{ Germination } \\
\cline { 2 - 3 } & No & Yes \\
\hline Selfed hermaphrodites & 33 & 107 \\
Outcrossed hermaphrodites & 10 & 130 \\
Outcrossed females & 20 & 100 \\
\hline
\end{tabular}

$\chi^{2}=14.35 ; \mathrm{df}=2 ; P=0.001$.

parents. In both studies, however, cross type was not controlled. Van Damme and Van Delden (1984), however, concluded that size of seedlings in the self-compatible gyndioecious Plantago lanceolata is independent of parent sex. Although greater survivorship of outcrossed progeny has been reported (Assouad et al., 1978), such differences were only statistically detectable in Silene acaulis three weeks after germination (Shykoff, 1988).

Several theoretical models have concluded that reduction of the fitness of selfed individuals and the resultant inbreeding depression may maintain females among hermaphrodites (Valdeyron et al., 1973; Lloyd, 1975; Assouad et al., 1978; Webb, 1981; Van Damme and Van Delden, 1984; Charlesworth and Charlesworth, 1978, 1987; Kesseli and Jain, 1984). The corollary, heterozygote advantage for fitness, also has been invoked as a possible mechanism for the maintenance of gynodioecy (Jain, 1961; Lloyd, 1975; Ross and Weir, 1976). Inbreeding depression has been documented or suggested in selfed progeny of normally outcrossed gynodioecious taxa (Ganders, 1978; Kesseli and Jain, 1984; Sun and Ganders, 1986; Sakai, Karoly, and Weller, 1989). We are reluctant to emphasize inbreeding depression exclusively in the maintenance of gynodioecy in Silene vulgaris at this time for several reasons. First, the differences among progeny due to pollen source are not significant if differences among maternal parent are factored into the design. Second, these data are from pollinations of naturally occurring individuals; our seedlings were not necessarily from inbred lines.
Lastly, without genotype data and more controlled male parentage, inbreeding depression can only be invoked in the most general sense and is indistinguishable from heterosis and pleiotropic effects. We can, however, conclude that offspring from hermaphrodites may be selected against, at least with respect to germinability. This slight selective advantage for females could maintain the equilibrium, particularly if the sex expression is nucleocytoplasmic (Charlesworth, 1981).

Empirical data do not consistently illustrate differences between females and hermaphrodites, nor among their progeny, predicted by theory. These inconsistencies relate to differences in biology among taxa, the relative stability of gynodioecy in the taxa, and our limited understanding of this breeding system. We present our work with Silene to illustrate that design and analysis also can limit as well as expand our understanding of plant mating systems.

The difference between the analysis based on one-way (completely randomized) design and that using the split-plot factorial design lies in the calculation of the $F$ statistic, computed as sum of squares (SSQ) for treatment divided by sum of squares for error. In the simple one-way design, all variation among seeds and seedlings is due to either group or random variation. The treatment sum of squares is actually composed of multiple sources of variation-differences among the type of cross, among the parents, and that due to random variation. As a result, the $F$ statistic in a one-way design is positively biased; it is too large due to the confounding of variation among different plants within a given sex into treatment sum of squares. This bias in the $F$ statistic would make one too likely to conclude significant treatment differences due to cross type. The split-plot factorial design takes these sources into account and partitions them into differences among seeds from a given cross and among plants within a given sex.

Our analysis of the split-plot factorial design leads us to conclude that differences in the progeny from selfed and outcrossed sexes with-

TABLE 7. Logistic regression comparing seed mass, sex of maternal parent, and type of cross to the likelihood of germination

\begin{tabular}{lccrc}
\hline \multicolumn{1}{c}{ Variable } & Regression coefficient & SE of coefficient & \multicolumn{1}{c}{$x^{2}$} & $P$ \\
\hline Seed mass & 5.7550 & 0.7695 & 55.94 & 0.0000 \\
Sex of maternal parent & -1.3110 & 0.4629 & 8.02 & 0.0046 \\
Cross type & -1.5803 & 0.4181 & 14.28 & 0.0002 \\
Intercept & -1.7128 & 0.6279 & 7.44 & 0.0064 \\
\hline
\end{tabular}

For all variables except the intercept, the regression coefficient is $B$, the slope of the regression line. 
TABLE 8. Means, standard deviations, sample sizes, and results of one-way analysis of variance for each of the five variables. Different superscripts indicate significant differences $(P \leq 0.05)$ among means

\begin{tabular}{|c|c|c|c|c|}
\hline Variable & $\bar{x} \pm \mathrm{SD}$ & & & \\
\hline Selfed hermaphrodites & Outcrossed hermaphrodites & Outcrossed females & $F$ & df \\
\hline \multicolumn{5}{|l|}{ Seed mass } \\
\hline $\begin{array}{c}0.84463^{b} \pm 0.24618 \\
(140)\end{array}$ & $\begin{array}{c}0.80935^{b} \pm 0.16471 \\
(140)\end{array}$ & $\begin{array}{c}0.91997^{a} \pm 0.29306 \\
(120)\end{array}$ & $7.20^{* * *}$ & 2,397 \\
\hline \multicolumn{5}{|l|}{ Days to germination } \\
\hline $\begin{array}{l}12.6^{b} \pm 3.021 \\
(105)\end{array}$ & $\begin{array}{c}12.0^{\mathrm{ab}} \pm 2.6 \\
(127)\end{array}$ & $11.6^{\mathrm{a}} \pm 2.3$ & $3.95^{*}$ & 2,328 \\
\hline \multicolumn{5}{|c|}{ Square root of leaf number } \\
\hline $2.84^{b} \pm 0.59$ & $\begin{array}{c}2.93^{\mathrm{ab}} \pm 0.52 \\
(115)\end{array}$ & $\begin{array}{c}3.04^{\mathrm{a}} \pm 0.50 \\
(97)\end{array}$ & $3.37^{*}$ & 2,293 \\
\hline \multicolumn{5}{|l|}{ Leaf area $\left(\mathrm{cm}^{2}\right)$} \\
\hline $\begin{array}{c}6.9^{b} \pm 4.0 \\
(84)\end{array}$ & $\begin{array}{c}9.0^{\mathrm{a}} \pm 4.4 \\
(115)\end{array}$ & $\begin{array}{c}9.4^{\mathrm{a}} \pm 4.5 \\
(96)\end{array}$ & $8.84^{* * * *}$ & 2,293 \\
\hline \multicolumn{5}{|c|}{ Square root of aboveground biomass } \\
\hline $\begin{array}{c}0.145^{\mathrm{b}} \pm 0.046 \\
(84)\end{array}$ & $\begin{array}{c}0.162^{\mathrm{a}} \pm 0.045 \\
(115)\end{array}$ & $\begin{array}{c}0.172^{a} \pm 0.050 \\
(97)\end{array}$ & $7.54^{* * *}$ & 2,293 \\
\hline
\end{tabular}

${ }^{*} P \leq 0.05 ;{ }^{* *} P \leq 0.01 ;{ }^{* * *} P \leq 0.001$.

in Silene vulgaris occur only within the early life history of the seedling, i.e., whether the seed germinates. Other gynodioecious taxa also exhibit differences in progeny from the different sexes early in development (Bonnemaison, Dommée, and Jacquard, 1979; Philipp, 1980; Couvet, Bonnemaison, and Gouyon, 1986). In order to balance the design, we used only those individuals that persisted during the entire experiment. Differences in survivorship may exist among the different types of progeny; we have begun these analyses. By six weeks of age, however, any differences among progeny due to mating system are obscured by larger differences among seedlings from different mothers. Size differences do occur between the sexes as adults; however, hermaphrodites are larger and produce more seed and flowers than do females (Jolls, 1984, and in preparation). Although this work dealt with progeny success in a controlled environment, differences in germinability among selfed and outcrossed progeny, at least from hermaphroditic parents, can be replicated in the field (Jolls, in preparation).

Differences among progeny in Silene vulgaris are attributable also to differences among mothers. It is unclear, however, whether such differences among progeny are due to differences in the genotypes of maternal parents or specific effects inherited only from mothers. Maternal effects can be significant determinants of seed size and seedling effects (Roach and Wulff, 1987). This study was not intended to investigate maternal effects; more appropriate designs exist (also see Roach and Wulff,
1987). Male sterility, however, is one of the best-known examples of maternal cytoplasmic inheritance. Most of the genetic bases for gynodioecy involve both nuclear and cytoplasmic factors (Couvet et al., 1986). These nuclear and cytoplasmic alleles for male sterility and the fertility restoring alleles may have important contributions to progeny fitness, adding yet another mechanism to explain the maintenance of females among hermaphrodites.

\section{LITERATURE CITED}

AEschimanN, D., AND G. BocQuet. 1980. Les types biologiques du Silene vulgaris s.l. (Caryophyllaceae). Candollea 35: 451-495. In French, English abstract.

Assouad, M. W., B. Dommée, R. Lumaret, AND G. VALDEYRON. 1978. Reproductive capacities in the sexual forms of the gynodioecious species Thymus vulgaris L. Bot. J. Linn. Soc. 77: 29-39.

Bonnemaison, F., B. Dommée, AND P. JaCQuard. 1979. Etude experimental de la concurrence entre formes sexuelles chez le thym, Thymus vulgaris. Oecol. PI. 14: 85-101.

Charlesworth, B., and D. Charlesworth. 1978. A model for the evolution of dioecy and gynodioecy. Amer. Naturalist 112: 975-997.

$\longrightarrow$ AND $\longrightarrow$ 1987. Inbreeeding depression and its evolutionary consequences. Annual Rev. Ecol. Syst. 18: 237-268.

Charlesworth, D. 1981. A further study of the problem of the maintenance of females in gynodioecious species. Heredity 46: 27-39.

ConNor, H. E. 1965. Breeding systems in New Zealand grasses. VI. Control of gynodioecism in Cortaderia richardii (Endl.) Zotov. New Zealand J. Bot. 3: 233242.

1970. Gynodioecism in Danthonia archboldii. Austral. J. Bot. 18: 233-236. 
1973. Breeding systems in Cortaderia (Gramineae). Evolution 27: 663-678.

Couvet, D., F. Bonnemaison, and P. GouYon. 1986. The maintenance of females among hermaphrodites: The importance of nuclear-cytoplasmic interactions. Heredity $57: 325-330$.

DaRWTN, C. R. 1877. The different forms of flowers on plants of the same species. J. Murray, London.

DOMMÉE, B., AND P. JACQUARD. 1985. Gynodioecy in thyme, Thymus vulgaris L.: evidence from successional populations. In $\mathrm{P}$. Jacquard et al. [eds.], Genetic differentiation and dispersal in plants, 141-164. Springer-Verlag, Berlin.

Downs, R. J., AND J. F. Thomas. 1983. Phytotron procedural manual for controlled environment research at the Southeastern Plant Environment Laboratory. North Carolina Agric. Res. Serv., North Carolina State Univ. Tech. Bull. 244 (rev.), Raleigh.

Dulberger, R., AND A. Horovitz. 1984. Gender polymorphism in flowers of Silene vulgaris (Moench) Garcke (Caryophyllaceae). Bot. J. Linn. Soc. 89: 101117.

GANDERS, F. R. 1978. The genetics and evolution of gynodioecy in Nemophila menziesii (Hydrophyllaceae). Canad. J. Bot. 56: 1400-1408.

GouYon, P. H., AND D. CouveT. 1985. Selfish cytoplasm and adaptation: variations in the reproductive system of thyme. In J. Haeck and J. W. Woldendorp [eds.], Phenotypic and genotypic variation within and between plant populations, 299-319. 2d Int. Symp. on the Structure and Functioning of Plant Populations. North-Holland, Amsterdam/New York.

Gregorius, H. R., M. D. Ross, AND E. Gillet. 1982. Selection in plant populations of effectively infinite size. III. The maintenance of females among hermaphrodites for a biallelic model. Heredity $48: 329$ 343.

JAIN, S. 1961. On the possible adaptive signifiance of male sterility in predominantly inbreeding populations. Genetics 46: 1237-1240.

Jolls, C. L. 1984. The maintenance of hermaphrodites and females in populations of Silene vulgaris (Moench) Garcke (Caryophyllaceae). Amer. J. Bot. 71: 80 .

Kesseli, R., AND S. K. JaIN. 1984. An ecological genetic study of gynodioecy in Limnanthes douglasil (Limnanthaceae). Amer. J. Bot. 71: 775-786.

KIRK, R. E. 1982. Experimental design, 2d ed. Brooks/ Cole, Monterey, CA.

Lefebvre, C., AND E. Simon. 1979. Plant spacing in open communities from old zinc-lead mine wastes. Oecol. Pl. 14: 461-473.

Lewrs, D. G. 1941. Male sterility in natural populations of hermaphroditic plants. New Phytol. 40: 56-63.

LLOYD, D. G. 1975. The maintenance of gynodioecy and androgynodioecy in angiosperms. Genetica 45: 325339.

- 1976. The transmission of genes via pollen and ovules in gynodioecious angiosperms. Theor. Pop. Biol. 9: 299-316.
Lubke, M. A., AND P. B. Cavers. 1970. Studies of vegetative regeneration in Saponaria officinalis L. (soapwort) and Silene cucubalus Wibel (bladder campion). Canad. Field-Naturalist 84: 43-47.

MoRRISSET, P. 1966. Tetraploid Silene vulgaris(Moench) Garcke in Europe. Bot. Soc. Brit. Isles Proc. 6: 278279.

Philipp, M. 1980. Reproductive biology of Stellaria longipes Goldie as revealed by a cultivation experiment. New Phytol. 85: 557-569.

RoACH, D. A., AND R. D. WulfF. 1987. Maternal effects in plants. Annual Rev. Ecol. Syst. 18: 209-235.

Ross, M. D. 1978. The evolution of gynodioecy and subdioecy. Evolution 32: 174-188.

_ _ AND B. S. WEIR. 1976. Maintenance of males and females in hermaphroditic populations and the evolution of dioecy. Evolution 30: 425-441.

Sakai, A. S., K. Karoly, and S. G. Weller. 1989. Inbreeding depression in Schiedea globosa and $S$. salicaria subdioecious and gynodioecious Hawaiian species. Amer. J. Bot. 76: 437-444.

SCHRAdER, P. J. 1986. Gynodioecy in Minuartia obtusiloba (Rydb.) House on Pennsylvania Mountain, Colorado. Ph.D. dissertation, University of California, Berkeley.

Shetler, S. G., AND L. E. Skog. 1978. A provisional checklist of species for Flora North America. Monogr. Syst. Bot. Missouri Bot. Gard. 1: 1-199.

SHYKofF, J. A. 1988. Maintenance of gynodioecy in $\mathrm{Si}$ lene acaulis (Caryophyllaceae): stage-specific fecundity and viability selection. Amer. J. Bot. 75: 844 850.

Stevens, D. P., AND A. J. Richards. 1985. Gynodioecy in Saxifraga granulata L. (Saxifragaceae). PI. Syst. Evol. 151: 43-54.

Sun, M., AND F. R. GANDERs. 1986. Female frequencies in gynodioecious population correlated with selfing rates in hermaphrodites. Amer. J. Bot. 73: 1645-1648.

VAARAMA, A., AND O. JÄÄSKELÄINEN. 1967. Studies on gynodioecism in the Finnish populations of Geranium silvaticum L. Ann. Acad. Sci. Fenn., Ser. A, IV. Biol. 108: 2-39.

VAldeYron, G., B. Dommée, AND A. Valdeyron. 1973. Gynodioecy: another computer simulation model. Amer. Naturalist 107: 454-459.

VAN Damme, J. M. M. 1984. Gynodioecy in Plantago lanceolata L. III. Sexual reproduction and the maintenance of male steriles. Heredity 52: 77-93.

$\longrightarrow$, AND W. VAN DELDEN. 1984. Gynodioecy in Plantago lanceolata L. IV. Fitness components of sex types in different life cycle stages. Evolution 38: 1326-1336.

WEBB, C. J. 1979. Breeding system and seed set in $E u$ onymus europaeus (Celastraceae). P1. Syst. Evol. 132: 299-303.

- 1981 . Test of a model predicting equilibrium frequencies of females in a population of gynodioecious angiosperms. Heredity 46: 397-405. 